\title{
UTILIZAÇÃO DE EXTRATO ENZIMÁTICO BRUTO PRODUZIDO A PARTIR DE RESÍDUO AGROINDUSTRIAL NA OTIMIZAÇÃO DA EXTRAÇÃO DE ÓLEO ESSENCIAL
}

\author{
I. M. C. TAVARES ${ }^{1 *}$, B. B. NASCIMENTO-JUNIOR ${ }^{2}$, M. FRANCO ${ }^{3}$
}

\author{
${ }^{1}$ Universidade Estadual Paulista, Departamento de Engenharia e Ciência de \\ Alimentos \\ ${ }^{2}$ Universidade Estadual de Santa Cruz, Departamento de Ciências Exatas e \\ Tecnológicas \\ ${ }^{3}$ Universidade Estadual do sudoeste da Bahia Department of Ciências Exatas \\ *e-mail: iasnaiamct@gmail.com
}

\begin{abstract}
RESUMO
Como alternativa à utilização de enzimas purificadas em processos, utilizouse extrato enzimático bruto no processo de extração de óleos essenciais, no intuito de simplificar e diminuir os custos de produção. No processo de produção desse extrato enzimático bruto utilizou-se como substrato sólido resíduo de bagaço de caju o que leva tanto à diminuição de custos como à ação poluidora dos resíduos gerados na produção e industrialização de alimentos. A aplicação do extrato enzimático bruto, produzido na fermentação dos resíduos de caju com auxilio do fungo Aspergillus niger, antes do processo de hidrodestilação, proporcionou uma elevação na percentagem de rendimento na extração do óleo essencial da planta Croton grewioides. No presente estudo foi observado o efeito do tempo de prétratamento e do volume de extrato enzimático bruto sobre o rendimento da extração. Independente do tempo de extração foi observado o aumento de aproximadamente $6 \%$, para extratos de caju. A atividade da enzima carboximetilcelulase indicou que a adição de $10 \mathrm{~mL}$ do "pull" de enzimas proporcionou um incremento de $0,194 \%$ de rendimento do óleo.
\end{abstract}

\section{INTRODUÇÃO}

A biodiversidade da flora existente no Brasil, em particular na região da caatinga representa um grande potencial para a produção de óleos essenciais, porém tal estudo deve ser realizado com responsabilidade, de modo a não acarretar o desaparecimento de duas espécies naturais (COSTA FILHO et al., 2012). É possível explorar essa biodiversidade vegetal através da extração de óleos essenciais de modo sustentável (SIANI et al., 2000).

Os óleos essenciais extraídos de muitas espécies vegetais oferecem ótimas condições para exploração econômica devido suas aplicações em fragrâncias, agricultura, pesticidas, alimentos entre outras. A exploração desses óleos é economicamente viável quando a planta a ser explorada 
apresenta alto rendimento e alta concentração de um composto orgânico. Alguns exemplos de constituintes de óleos essenciais com exploração econômica são; o safrol (70-95\%) em Piper hispidinervum e Piper callosum; a $\alpha$ tujona (95\%) em Tanacetum suaveolens; Apiol (80\%) em Piper krukoffii; $\alpha$-pineno (70 $\%)$ em lchthyothere cunabi além dessas plantas as do gênero Croton, se destaca devido as altas concentrações de compostos químicos importantes para a indústria farmacêutica e alimentícia, como o eugenol (essência de cravo) e o methilchavecol (essência de erva-doce) (MAIA \& ANDRADE, 2009).

Normalmente esses óleos estão armazenados em estruturas anotômicas especificas como os tricomas (ALAIMO, 2005). Na extração dos óleos podem ser aplicadas diversas técnicas como a including supercritical fluid extraction, pressurized liquid extraction, pressurized hot water extraction, hydrothermal extraction, water vapour extraction, solvent extraction, membrane-assisted solvent extraction, solidphase microextraction, stir bar sorptive extraction, microwave-assisted extraction, and hydrodistillation (FLAMINI et al., 2007)

A hidrodestilação é um método de extração de óleo essencial tradicional largamente utilizado em escala laboratorial (YAMINI, 2007). Os métodos mais modernos, apesar de serem mais onerosos, sanam desvantagens da hidrodestilação como a baixa eficiência, e as perdas e degradação de alguns compostos voláteis devido aos longos tempos de extração (LUCCHESI et al., 2004) (OKOH et al., 2010).

A aplicação de enzimas celulolíticas é uma alternativa para otimizar processo de extração de óleos, pois consegue elevar a quantidade extraída e diminui o tempo de extração (WU et al., 2009) (CHABRAND \& GLATZ, 2009) (DUSSAN et al., 2010) (YOU et al., 2011). Estas enzimas degradam a parece celular, rompendo da estrutura celular e facilitando assim a extração de óleos (JUGE, 2006) (ARO et al., 2004). Microrganismos celulolíticos conhecidas como verdadeiros, que são aqueles capazes de degradar a celulose natural. Celulases podem ser produzidos por fungos ou bactérias, sendo as enzimas fúngicas com mais aplicações comerciais devido aos seus elevados níveis de produção (CHANG, 2007; DIENES, EGYFAZI, RECZEY, 2004).

As duas principais estratégias para a produção de celulases são a fermentação no estado sólido (SSF) e a fermentação submersa $(\mathrm{SF})$, que diferem entre si no que diz respeito às aos meios e as formas de realização. Um dos parâmetros mais eficientes em diferenciar estes tipos de processos é, sem dúvida, a análise do volume de água presente na reação (PANDEY, 2003; MAZUTTI et al., 2010.). O nível de atividade da água com a finalidade de assegurar um crescimento e metabolismo das células, por outro lado, não exceda a capacidade de ligação máxima da água com matriz sólida (GERVAIS \& MOLIN, 2003). $\mathrm{O}$ fungo filamentoso Aspergillus é considerada de grande importância econômica devido à sua produção de metabólitos, tais como enzimas (SHARMA, CHISTI, BANERJEE, 2001; PELIZER et al., 2007;. GRAMINHA, GONÇALVES, PIROTA, BALSALOBRE, GOMES, 2008).

Apesar de diversos estudos desenvolvidos demonstrarem a eficiência desse processo o alto custo econômico das enzimas inviabiliza sua aplicação industrial. O custo de produção dos extratos enzimáticos depende de diversos fatores, como a quantidade e $\mathrm{o}$ processo de produção e recuperação, grau de pureza, entre outras (SAID \& PIETRO, 2004).

Além do método alternativo para a produção de enzimas é possível utilizar o extrato enzimático bruto, sem a necessidade de purificação, essa possibilidade pode reduzir os custos operacionais e viabilizar a 
aplicação de extratos enzimáticos no processo de extração dos óleos essenciais.

\section{MATERIAIS E MÉTODOS}

\subsection{Materiais}

As folhas do gênero Croton grewioides, foram coletadas na região semiárida da Bahia na cidade de Jequié. Os resíduos de acerola (Malpighia emarginata D.C.) e de caju (Anacardium occidentale L.) foram cedidos por uma agroindústria de beneficiamento de polpa de frutas localizada na cidade de Ipiaú/BA. O fungo filamentoso Aspergillus niger foi obtido de uma cepa pertencente ao Laboratório de Reaproveitamento de Resíduos Agroindustriais da UESB. Os cabeçalhos de segunda ordem devem ser alinhados à margem esquerda, em negrito, sendo a primeira letra de cada palavra em maiúsculo. Deve existir um espaço separando o segundo cabeçalho do texto anterior.

\subsection{Obtenção dos esporos Solução}

A cultura esporulada (inclinado, acidificada PDA HIMEDIA) foi suspenso numa solução de $1 \%$ de Tween 80 (VETEC). $\mathrm{O}$ número de esporos em suspensão foi contada utilizando uma câmara de Neubauer espelho duplo e um microscópio binocular Bioval L1000. A quantidade de $10^{7}$ esporos por grama de substrato base seca foi adicionada à suspensão.

\subsection{Produção de extrato enzimático "pull"}

Os ensaios foram realizadas em frascos de Erlenmeyer contendo 10 gramas de resíduo seco, ao qual foram adicionados $50 \%$ de água esterilizada. As incubações foram conduzidas por 48 horas em um modelo de estufa bacteriológica SOLAB número SL 101.

\subsection{Extração enzimática da "Pull"}

Seguindo o processo de fermentação, o extrato de enzima foi extraída mecanicamente utilizando uma solução tampão de citrato de sódio (VETEC) com um $\mathrm{pH}$ de 4,8 a $50 \mathrm{mM}$. $\mathrm{O}$ extrato de enzima que resulta da fermentação foi centrifugado a $2000 \mathrm{rpm}$ durante 10 minutos numa centrífuga CETRIBIO 80-2B.

\subsection{Determinação da atividade de CMCase}

$\mathrm{O}$ método escolhido para determinar a atividade de CMCase e que representa a dose de endoglucanases baseia-se na dose de açúcares redutores produzidos (GHOSE, 1987) por a degradação de carboximetilcelulose (CROMOLINE) a $2 \%(\mathrm{p}$ / v), previamente diluído em uma solução de citrato de sódio com pH de 4,8 a $50 \mathrm{mM}$. O método do ácido dinitrossalicilico foi usado para a quantificação (DNS) (MILLER, 1959).

\subsection{Pré-tratamento enzimático}

Folhas de Croton Grewioides (36 g) foram tratados com o extrato bruto enzimático. A mistura foi misturada teve o $\mathrm{pH}$ $(5,0)$ do material ajustado para ácido cítrico aquoso e incubou-se a $50{ }^{\circ} \mathrm{C}$ por um período de 60 minutos (SOWBHAGYA, SRINIVAS \& KRISHNAMURTHY, 2010 E SOWBHAGYA, et al., 2009).

\subsection{Extração do óleo essencial}

Folhas de Croton Grewioides (36 g) e extrato enzimático bruto, obtidos com e sem (controle) pré-tratamento, foram colocadas em aparelho de Clevenger para a hidrodestilação. O óleo essencial recolhida no aparelho foi removido e seco sobre sulfato de sódio anidro. O rendimento do óleo obtido foi expressa como uma percentagem.

\subsection{Análises cromatográficas}

Os óleos essenciais foram analisados por cromatografia gasosa em um CG-FID (cromatógrafo gasoso com detector de ionização por chama) Varian, modelo 3800 para identificação e análise de possível alteração dos constituintes voláteis presentes nos óleos essenciais. As condições 
cromatográficas foram: Coluna DB5 (30m x $0,25 \mathrm{~mm}$ i.d. $\mathrm{x} 0,25 \mu \mathrm{m})$; Temperatura inicial de $50^{\circ} \mathrm{C}$; Tempo inicial de 2 minutos; Tempo final de 70 minutos; Temperatura final de $240^{\circ} \mathrm{C}$; Temperatura do injetor de $240^{\circ} \mathrm{C}$; Temperatura do detector de $280^{\circ} \mathrm{C}$; Gás de arraste nitrogênio; Programação de temperatura: $50^{\circ} \mathrm{C}$ até $280^{\circ} \mathrm{C}$ com rampa de aquecimento de $20^{\circ} \mathrm{C} / \mathrm{min}$. Modo de injeção com divisão de fluxo de 1:50.

Para serem injetadas no CG, todas as amostras de óleo foram diluídas em diclorometano, para serem injetadas na coluna, em uma proporção de $10 \mu \mathrm{L}$ de óleo para $1 \mathrm{~mL}$ de (1:100) diclorometano. Além de diclorometano e óleo, as amostras injetadas também continham uma terceira substância que foi utilizada como padrão interno, o anizol, em concentração idêntica ao do óleo $(1 \mu \mathrm{L})$. Através da razão entre o óleo e o anizol, foi possível saber se houve alteração quantitativa dos constituintes do óleo em função dos tratamentos e a variação na concentração destes constituintes.

\subsection{Analises estatísticas}

As análises estatísticas necessárias foram realizadas no pacote estatístico Statystical Analysis System ${ }^{\circledR}$ versão 9.0, procedimentos GLM e REG (SAS Institute Inc., Cary, NC, USA), licenciado pela Universidade Federal de Viçosa. Foi utilizado o teste $\mathrm{F}$ para as Análises de Variância (ANOVA) a $5 \%$ de probabilidade.

Aos dados experimentais foram ajustados modelos lineares, observando $\mathrm{o}$ coeficiente de determinação e a concordância com o fenômeno estudado. Os modelos foram avaliados e os respectivos gráficos construídos, utilizando o software SigmaPlot® 11.0.

\section{RESULTADOS E DISCUSSÃO}

\subsection{Otimização do tempo de extração}

Na Tabela 1 estão apresentados os valores médios das massas de óleo essencial extraído sem pré-tratamento com EEB (OS), óleo essencial extraído após pré-tratamento com EEB obtido a partir da fermentação de resíduo de caju (OC), recolhido em tempos de 1 a 4 horas, assim como o rendimento obtido.

Tabela 1: Massa do óleo essencial obtido com e sem pré-tratamento com EEB, produzido a partir de resíduo de caju e acerola recolhido após diferentes tempos de extração e seu rendimento

\begin{tabular}{|c|c|c|c|c|}
\hline \multirow{2}{*}{$\begin{array}{c}\text { Tempo } \\
\text { de } \\
\text { extração } \\
\text { (h) }\end{array}$} & \multicolumn{3}{|c|}{ OS } & OC \\
\hline & $\begin{array}{c}\text { Massa* } \\
(\mathrm{g})\end{array}$ & $\begin{array}{c}\text { Rendimento } \\
(\%)\end{array}$ & $\begin{array}{c}\text { Massa* } \\
(\mathrm{g})\end{array}$ & $\begin{array}{c}\text { Rendimento } \\
(\%)\end{array}$ \\
\hline 1 & $1,031 \pm 0,086$ & 2,86 & $1,082 \pm 0,078$ & 3,00 \\
\hline 2 & $1,053 \pm 0,081$ & 2,93 & $1,116 \pm 0,072$ & 3,10 \\
\hline 3 & $1,070 \pm 0,077$ & 2,97 & $1,145 \pm 0,078$ & 3,18 \\
\hline 4 & $1,083 \pm 0,071$ & 3,01 & $1,159 \pm 0,082$ & 3,22 \\
\hline $\begin{array}{l}{ }^{*} \mathrm{Va} \\
\text { extra } \\
\text { pré-t } \\
\text { tratar }\end{array}$ & $\begin{array}{l}\text { es de massas } \\
\text { es realizadas e } \\
\text { amento com EE } \\
\text { nto com EEB ob }\end{array}$ & $\begin{array}{l}\text { orrespondem } \\
\text { duplicata. OS } \\
\text { (OS); OC = ól } \\
\text { do a partir da fe }\end{array}$ & $\begin{array}{l}\text { média } \pm \text { desvio } \\
\text { óleo essencial } \\
\text { essencial extraí } \\
\text { lentação de resí }\end{array}$ & $\begin{array}{l}\text { oadrão de } \\
\text { raído sem } \\
\text { após pré- } \\
\text { o de caju. }\end{array}$ \\
\hline
\end{tabular}

Em todos os tempos de extração, o rendimento dos óleos extraídos após aplicação de EEB na etapa de pré-tratamento foi maior do que o rendimento do óleo extraído sem a utilização dos extratos enzimáticos. Para todos os casos o rendimento foi crescente ao passar do tempo de extração. Após quatro horas de extração, tempo máximo utilizado, o rendimento do OS foi de $3,01 \%$, enquanto do OC. Isso demonstra a eficiência da aplicação dos EEBs, pois houve aumento do rendimento dos óleos extraídos utilizando extrato enzimático.

Pode ser observado que, logo na primeira hora, o rendimento da extração de OC foi praticamente igual ao de OS com 4 horas de extração. Isso possibilita a redução do tempo de extração nos processos com a utilização das enzimas, diminuindo o custo do processo e possíveis alterações químicas durante a extração de óleos pouco estáveis. 


\subsection{Otimização do volume de enzima}

Os experimentos utilizando diferentes concentrações de EEBs na etapa de prétratamento demonstraram a eficácia da utilização destes extratos enzimáticos, com um aumento máximo médio de $10,01 \%$, para a produção de óleo, em relação à extração sem a aplicação das enzimas. Foram utilizadas concentrações de EEB/tampão crescentes os tratamentos com resíduos, e somente tampão nos tratamentos controles.

$\mathrm{Na}$ Tabela 2 estão apresentados os valores dos volumes utilizados de EEB, proveniente da fermentação do resíduo de caju, que variam de 150 a $550 \mathrm{~mL}$. Também estão apresentados os valores das massas do óleo extraído, com e sem o auxílio destas enzimas, e o aumento desta massa em porcentagem, que variaram entre 2,88 a $10,01 \%$.

Tabela 2: Aumento da massa de óleo essencial de Croton grewioides, após 1 hora de extração, utilizando extrato enzimático bruto obtido a partir de resíduo de caju.

\begin{tabular}{|c|c|c|c|c|}
\hline Amostra & & \multicolumn{3}{|c|}{ Massa de óleo obtida $(\mathrm{mg})^{\star}$} \\
\hline S/extrato & $\begin{array}{c}\text { Extrato } \\
\text { enzimático } \\
(\mathrm{ml})\end{array}$ & C/extrato & $\begin{array}{l}\text { Aumento } \\
\text { do óleo } \\
\text { extraído } \\
\text { (\%) }\end{array}$ & \\
\hline 1 & 150 & 488,5 & 503 & 2,88 \\
\hline 2 & 250 & 472 & 493 & 4,25 \\
\hline 3 & 350 & 544 & 583 & 6,7 \\
\hline 4 & 450 & 564,6 & 515 & 8,72 \\
\hline 5 & 550 & 607 & 681 & 10,1 \\
\hline
\end{tabular}

A partir da análise estatística ANOVA dos resultados experimentais, observou-se que houve diferença significativa para a massa de óleo extraído com e sem pré-tratamento com EEB, a 5\% de probabilidade pelo teste F. Essa diferença ocorreu, possivelmente, influenciada pela diferença entre os tipos e das proporções de enzimas presentes nos EEB, produzidos a partir de resíduo de caju. Analisando o comportamento da curva
(Figura 1), percebe-se que a quantidade de EEB aplicado no pré-tratamento para a extração de óleo exerceu influência, ou seja, com o aumento do volume de EEB aplicado, houve um aumento da extração de óleo.

Figura 1 - Aumento da massa de óleo essencial extraída, pelo volume de EEB produzido a partir de resíduo de caju, utilizado no pré-tratamento das folhas de Croton grewioides.

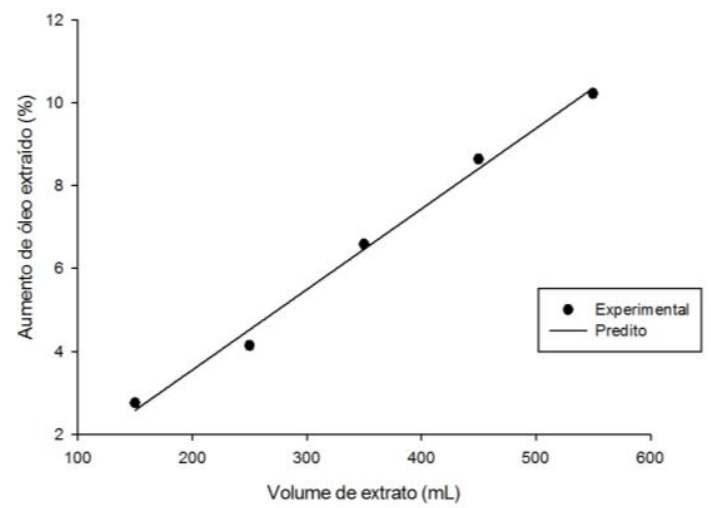

Os resultados obtidos de aumento da extração do óleo essencial em função da concentração enzimática de CMCase foram bem ajustados no modelo linear (Equações 1), $\mathrm{R}^{2}$ igual a 0,992 , para os valores apresentados na Figura 1, sendo todos os parâmetros significativo $(\mathrm{P}<0,001)$. De acordo com estas equações, a variação positiva de um $\mathrm{mL}$ no volume de EEB aplicado na etapa de prétratamento, acarreta no aumento de $0,0194 \%$ de aumento da massa do OC.

$R=-0,3326+0,0194 V R=0,992$

O uso de enzimas na extração de óleos vegetais foi pesquisado intensamente há alguns anos e aplicado para todas as oleaginosas de interesse comercial, como mostrado nos trabalhos de revisão publicados por Rosenthal et al. (1996), Freitas et al. (1996) e Dominguez et al. (1994). Porém esta tecnologia é pouco empregada na indústria, em razão do alto custo das enzimas 
purificadas, o que diferencia deste trabalho onde utilizamos extratos enzimáticos brutos.

Em trabalho realizado por Sowbhagha et al (2010), testou-se quatro enzimas purificadas na extração de óleo volátil de aipo. $\mathrm{O}$ rendimento de óleo volátil, depois de aplicação individual por pulverização de celulase, pectinase, protease e viscozyme no pré-tratamento, teve aumento de 22 a $27 \%$.. A obtenção do óleo foi por hidrodestilação, sendo observada uma alteração na composição dos seus constituintes, o terpeno principal e o limoneno aumentaram sua concentração de $63 \%$ para $82 \%$ com tratamento enzimático; outros compostos principais tiveram alterações menos significativas, de 16 a 17\%, o que não ocorreu neste trabalho.

\subsection{Cromatografia gasosa}

Através dos cromatogramas obtidas por meio de GC-FID, verificou-se a presença de um único composto majoritário, o metilchavicol, em todas as amostras (sem e com tratamento enzimático e de tempos de 1 a 4 horas). Assim, alterações na composição química dos $\mathrm{OC}$ decorrentes da exposição a altas temperaturas por um longo período de tempo ou ainda pela influência do EEB, não foram observadas.

Também não foi verificada nenhuma alteração na composição química dos óleos extraídos, nem a incorporação de nenhuma substância volátil do extrato enzimático, Mesmo com a utilização de concentrações máximas de EEB de caju

Os cromatogramas de todas as amostras apresentaram picos idênticos, como os apresentados na Figura 2. O primeiro pico que apresenta tempo de retenção de aproximadamente $\quad 0,7 \quad$ minutos é correspondente ao solvente utilizado na amostra, o diclorometano. O segundo pico que aparece no tempo de aproximadamente 3,3 minutos é referente ao padrão interno, que é o anizol, já o terceiro pico que apresenta tempo de retenção de aproximadamente de 5,9 minutos, é referente à substância presente no óleo, o metilchavicol. A razão entre as áreas dos picos do anizol e do metilchavicol é de aproximadamente 1, o que leva ao entendimento que o óleo está praticamente puro, podendo conter somente traços de outras substâncias, e que não houve alteração de sua constituição química, nem incorporação de outras substâncias voláteis.

Figura 2 - Cromatograma referente ao OC após pré-tratamento com $550 \mathrm{ml}$ de EEB.



\section{Conclusão}

Aplicando-se EEBs na etapa de prétratamento aumentou o rendimento do óleo extraído, comprovando-se assim a eficácia da utilização dos mesmos. Houve um aumento máximo da massa do óleo extraído em 10,1\%, para o resíduo de caju, sendo que maiores concentrações de enzimas interferem diretamente na quantidade de óleo extraído.

\section{AGRADECIMENTOS}

Os autores agradecem à Fapesb (Fundação de Amparo á pesquisa da Bahia), ao Conselho Nacional de Desenvolvimento Científico e Tecnológico (CNPq) para a concessão da bolsa de estudos ITI (Iniciação Tecnológica Industrial) e o Brasil Banco do Nordeste (BNB) para a concessão de apoio financeiro. 


\section{REFERÊNCIAS}

ALAIMO, M. G., VIZZI, D., MELATI, M. R. Histochemical properties and trace element concentrations in Parietaria L. from urban sites. Aerobiologia, v. 21, p. 21-31, 2005.

ARO, N., PAKULA, T., \& PENTTILÃ, M. Transcriptional regulation of plant cell wall degradation by filamentous fungi. FEMS Microbiology Reviews, v. 29, p. 719-739, 2005.

CHABRAND, R.M., GLATZ, C. E. Destabilization of the emulsion formed during the enzyme-assisted aqueous extraction of oil from soybean flour. Enzyme and Microbial Technolog, v. 45, p. 28-35, 2009.

CHANG, M. Harnessing energy from plant biomass. Current Opinion, Chemical Biology, v. 11, p. 677-684, 2007.

COSTA FILHO, L. O., SILVA, M. H. M., ALMEIDA-CORTEZ, J. S., SILVA, S. I., OLIVEIRA, A. F. M. Foliar cuticular nalkane of some Croton species from Brazilian semiarid Vegetation. Biochemical Systematics and Ecology, v. 41, p. 13-15, 2012.

DOMINGUEZ, H., NÚÑEZ, M. J., LEMA, J. M. Enzymatic pretreatment to enhance oil extraction from fruits and oilseeds: a review. Food Chemistry, v. 49, p. 271-286, 1994.

DUSSAN, K.J., CARDONA, C.A., GIRALDO, O.H., GUTIÉRREZ, L.F., PÉREZ, V.H. Analysis of a reactive extraction process for biodiesel production using a lipase immobilized on magnetic nanostructures. Bioresource Technology, v. 101, p. 9542-9549, 2010.

FATOPE, M. O., MARWAH, R. G., HADHRAMI, N. M., ONIFADE, A. K.,
WILLIAMS， J. R. Identification of the Chemotypes of Ocimum forskolei and Ocimum basilicum by NMR Spectroscopy. Chemistry \& Biodiversity, v. 5 , p. 2457 2463, 2008.

FLAMINI, G., TEBANO, M., CIONI, P. L., CECCARINI, L., RICCI, A. S., LONGO, I. Comparison between the conventional method of extraction of essential oil of Laurus nobilis L. and a novel method which uses microwaves applied in situ, without resorting to an oven. Journal of Chromatography A, v. 1143, p. 36-40, 2007.

FREITAS, S., HARTMAN, L., COURI, S. Alternativa biotecnológica ao uso de solventes orgânicos na extração de óleos vegetais. Óleos e Grãos, v. 32, p. 29-32, 1996.

JUGE, N. Plant protein inhibitors of cell wall degrading enzymes. Review Article. Trends in Plant Science, v. 11, p. 359-367, 2006.

LUCCHESI, M. E., CHEMAT, F., SMADJA, J. Solvent-free microwave extraction of essential oil from aromatic herbs:comparison with conventional hydro-distillation. Journal of Chromatography A, v. 1043, p. 323-327, 2004.

MAIA, J. G. S., ANDRADE, E. H. A. Database of the amazon aromatic plants andtheir essential oils. Química Nova, v. 15, p. 1-29, 2000.

MARTINS, E. R., CASALI, V. W. D., BARBOSA, L. C. A., CARAZZA, F. Essential oil in the taxonomy of Ocimum selloi Benth.. Journal Brazilian Chemistry society, v. 8, p. 29-32, 1997.

MILLER, G. L. Use of dinitrosalicylic acid reagent for determination of reducing sugar. Analytical Chemistry, v. 1, p. 426-28, 1959. 
OKOH, O. O., SADIMENKO A. P., AFOLAYAN A. J. Comparative evaluation of the antibacterial activities of the essential oils of Rosmarinus officinalis L. obtained by hydrodistillation and solvent free microwave extraction methods Original Research. Food Chemistry, v. 120, p. 308-312, 2010.

ROSENTHAL, A., PYLE, D. L., NIRANJAN, K. Aqueous and enzymatic processes for edible oil extraction: a review. Enzyme and Microbial Technology, v. 19, p. 402-420, 1996.

SIANI, A. C., SAMPAIO, F. L. A., SOUSA, C. M., HENRIQUE, O. M. G. M., \& RAMOS, S. F. M. Óleos essenciais. Biotecnologia Ciências e Desenvolvimento, p. 3, n. 37-43, 2000.

SOWBHAGYA, H. B., PURNIMA, K. T. FLORENÇA, S. P., RAO, A. G. A., SRINIVAS, P. Evaluation of enzyme-assisted extraction on quality of garlic volatile oil. Food Chemistry, v. 113, n. 1234-1238, 2009.

SOWBHAGYA, H. B., SRINIVAS, P., \& KRISHNAMURTHY, N. Effect of enzymes on extraction of volatiles from celery seeds. Food Chemistry, n. 120, p. 230-234, 2010.

WU, J., JOHNSON, L.A., JUNG, S. Demulsification of oil-rich emulsion from enzyme-assisted aqueous extraction of extruded soybean flakes. Bioresource Technology, v. 100, p.527-533, 2009.

YAMINI, Y., KHAJEH M., GHASEMI, E., MIRZA M., JAVIDNIA, K. Comparison of essential oil compositions of Salvia mirzayanii obtained by supercritical carbon dioxide extraction and hydrodistillation methods. Food Chemistry, v. 108, n. 41-346, 2008.
YOU, J.-Y., PENG, C., LIU, X., JI, X.-J., LU, J., TONG, Q., WEI, P., CONG, L., LI, Z., HUANG, H. Enzymatic hydrolysis and extraction of arachidonic acid rich lipids from Mortierella Alpine. Bioresource Technology, v. 102, p. 6088-6094, 2011. 